\title{
An investigation of Australian osteopaths' attitudes, skills and utilisation of evidence- based practice: a national cross-sectional survey
}

Matthew J. Leach ${ }^{1,2}$, Tobias Sundberg ${ }^{2,3}$ Gary Fryer $^{4^{*}}$ (D) Philip Austin $^{5}$, Oliver P. Thomson ${ }^{6,7}$ and Jon Adams ${ }^{2}$

\begin{abstract}
Background: Osteopaths are an integral member of the health care team, playing a pivotal role in the provision of care for patients with musculoskeletal disorders. Osteopaths, like other health care providers, are under increasing pressure to deliver evidence-based health care and to improve patient outcomes. However, the extent to which osteopaths engage in evidence-based practice (EBP), particularly in Australia, is not well understood. This study therefore set out to investigate the attitudes, skills and use of EBP, and perceived barriers and enablers of EBP uptake, among osteopaths practicing in Australia.
\end{abstract}

Methods: National cross-sectional survey of Australian registered osteopaths. Eligible participants were invited by email and other digital media recruitment strategies to complete the online Evidence-Based Practice Attitude and Utilisation Survey (EBASE).

Results: A total of 332 osteopaths completed the survey. The demographic characteristics of respondents were generally consistent with the characteristics of the Australian osteopathy workforce. The respondents were mostly favourable of EBP, with the majority agreeing or strongly agreeing that EBP assists in making decisions about patient care (86.7\%) and improves the quality of patient care (75.6\%). While most respondents (88.3\%) had some training in EBP, most reported a moderate level of perceived skill in EBP. The majority of respondents engaged infrequently ( $0-5$ times) in EBP activities within the last month, and most indicated that a very small or small proportion of their clinical practice was based on clinical research evidence. Leading barriers to the uptake of EBP were lack of time and lack of clinical evidence in osteopathy. Key enablers of EBP uptake were access to the internet and online databases at work, and access to full-text articles and EBP education materials.

Conclusions: Osteopaths participating in the survey were largely supportive of evidence-based practice, yet engaged infrequently in EBP activities. An important next step in this research is to identify suitable strategies that effectively improve EBP uptake in osteopathy, and perchance, improve patient outcomes.

Keywords: Attitude, Barriers, Enablers, Evidence-based practice, Osteopathy, Skill, Survey, Training

\footnotetext{
*Correspondence: gary.fryer@vu.edu.au

${ }^{4}$ College of Health \& Biomedicine, Victoria University, Melbourne, Victoria,

Australia

Full list of author information is available at the end of the article
}

(c) The Author(s). 2019 Open Access This article is distributed under the terms of the Creative Commons Attribution 4.0 International License (http://creativecommons.org/licenses/by/4.0/), which permits unrestricted use, distribution, and reproduction in any medium, provided you give appropriate credit to the original author(s) and the source, provide a link to the Creative Commons license, and indicate if changes were made. The Creative Commons Public Domain Dedication waiver (http://creativecommons.org/publicdomain/zero/1.0/) applies to the data made available in this article, unless otherwise stated. 


\section{Background}

Osteopathy has been described as a person-centred approach to manual therapy that focuses on the neurological, musculoskeletal and visceral structures of the body [1]. Osteopaths typically utilise a range of therapeutic interventions (including manual therapy, exercise and lifestyle advice) to manage diverse health complaints, although neuro-musculoskeletal conditions are the predominant focus. In 2013, there were an estimated 130,850 osteopaths / osteopathic physicians practicing in 33 countries across the globe [1]. In Australia - where osteopaths are considered primary care professionals - there were 2 , 277 practicing registered osteopaths (in 2018) [2].

Osteopaths play an important role in the delivery of musculoskeletal healthcare. In fact, musculoskeletal back pain is the leading reason why patients consult an osteopath [1]. As for the level of service provision, findings from a recent survey of the Australian osteopathy workforce suggest that osteopaths manage approximately 3.9 million patients per year. With osteopaths working 28 clinical hours per week on average, this equates to an estimated 3 million hours per year of patient care [3].

Osteopathy has achieved some form of national statutory regulation in a number of countries across the world, including several European countries, the UK, New Zealand and Australia [4]. The development of osteopathy from its inception in the USA during the late 1800 s, has taken different paths globally over the course of time. The most marked differences can be found between 'osteopathic physicians' and 'osteopaths'.

Osteopathic physicians primarily work in the USA, and are licensed to practice the full scope of medicine, including surgery and the prescription of medications, but they rarely specialise in the use of manual therapy techniques in practice [5]. By contrast, osteopaths, practicing outside of the USA, focus on the diagnosis, treatment, prevention and rehabilitation of musculoskeletal disorders, and the effects of these conditions on a patients' general health, using predominantly hands-on manual therapy skills [6-8]. It is worth noting that a range of professional views and identities reside within osteopathy [9-11], and there is continued debate across the profession globally as to the particular theoretical, philosophical, and evidential underpinnings that define osteopathy and guide clinical practice and reasoning [12-14].

The role that research evidence plays in informing osteopathy practice and clinical decision-making is another area that has been keenly discussed across the globe [15-19]. Developed in the early 1990s [20], evidence-based medicine has been ubiquitously defined as the conscientious, explicit and judicious use of current best evidence in making decisions about the care of individual patients [21]. From its conception, evidence-based medicine and subsequent iterations, including evidence-based practice (EBP), emphasised that research evidence should be integrated with a clinician's expertise (i.e. proficiency, values and judgment) [21]. In more recent times, there has been an increasing emphasis on the role of the patient in EBP (by incorporating a patient's individual values, preferences and experiences in a process of shared decisionmaking) [22, 23].

Recent research has highlighted several challenges with embedding EBP into osteopathic practice and education. For example, in a survey of 370 UK osteopaths, Weber and Rajendran [24] found that even though osteopaths had largely positive attitudes towards EBP, a perceived lack of time and an inability to apply research evidence to individual patients were perceived barriers to EBP uptake. Similarly, findings from qualitative research have highlighted tensions between traditional osteopathic theory and EBP amongst UK osteopaths [12]; whereby knowledge, theory and opinion gathered from prominent individual 'experts' throughout osteopathy's development from the 1800s frequently took precedence over external research evidence when making clinical decisions $[25,26]$. Further qualitative research involving Australian osteopaths has also identified a perceived fear among clinicians that EBP will diminish or undermine the application of traditional osteopathic theory that is perceived to be unique to the profession [10]. In the context of this current study, these findings are important as some professional groups in Australia, specifically GPs, perceive there to be a lack of research evidence supporting osteopathic care [27, 28]; as gatekeepers of secondary and tertiary health care, GP (and other health provider) perceptions may represent a legitimate barrier to patient referral for publicly-funded osteopathy services in Australia.

Our previous research examined the barriers and facilitators of EBP uptake amongst UK osteopaths [29]. The work identified lack of time and a paucity of clinical evidence in osteopathy as key barriers to EBP uptake; access to online databases, internet at work, full-text articles, and EBP education materials were perceived to be important enablers of EBP utilisation. Whether these findings apply to osteopaths in Australia is unknown. Therefore, the aim of the study described herein was to investigate Australian osteopaths' attitudes, skills and utilisation of research evidence in practice, their training in EBP, as well as the barriers and enablers of EBP uptake.

\section{Methods \\ Design}

National, cross-sectional survey. 


\section{Research questions}

The study was designed to answer the following research questions:

1. To what extent do Australian osteopaths engage in evidence-based practice (EBP)?

2. What level of importance do Australian osteopaths place on EBP?

3. What factors enable Australian osteopaths to practice EBP?

4. What barriers prevent Australian osteopaths from practicing EBP?

5. What skills and level of training do Australian osteopaths possess in order to practice EBP?

6. What types of interventions would facilitate Australian osteopath uptake of EBP?

7. Is there an association between practitioner demographics, and EBP use, skill and attitude?

\section{Sample and setting}

All osteopaths registered with the Osteopathy Board of Australia (OBA), and practicing osteopathy in any state or territory in Australia, were eligible to participate in the study. Based on a target population of 2,277 practicing registered osteopaths (as at 31st March 2018) [2], the study required at least 329 respondents in order to achieve a $5 \%$ margin of error with $95 \%$ confidence for any individual item on the survey.

\section{Measurement}

Practitioner attitudes, perceived skill, training and utilisation of EBP, and the barriers and enablers of EBP uptake, were measured using the Evidence-Based practice Attitude and utilization Survey (EBASE). This instrument has been administered to diverse practitioner populations to date, including chiropractors [30-32], herbalists [33, 34], naturopaths [33], yoga therapists [35] and nursing students [36]. EBASE has also undergone psychometric evaluation, and has been shown to have good internal consistency, construct validity, content validity, and acceptable test-retest reliability [37, 38].

The 84-item EBASE instrument comprises seven parts, with each part measuring a different construct: Part A (attitude toward EBP), Part B (EBP-related skills), Part C (EBP-related training), Part D (use of EBP), Part $\mathrm{E}$ (barriers to EBP uptake), Part $\mathrm{F}$ (enablers of EBP uptake), and Part G (demographic characteristics). Three subscores can be generated from EBASE: an attitude subscore, skill subscore and use subscore. The scoring procedures and parameters of these subscores are reported in detail elsewhere [32].

As EBASE was originally written for a general complementary and alternative medicine (CAM) audience, some terminology had to be modified to ensure the survey was relevant to Australian osteopaths. Specifically, the term CAM was replaced with osteopathy, and the response options of two demographic questions were revised (i.e. types of treatment / management typically provided in the first consultation; professional association membership). These minor amendments did not change the meaning of the questions, and therefore, did not impact the validity or reliability of EBASE.

\section{Recruitment and data collection}

Eligible participants were invited to participate in the survey via a range of digital recruitment strategies. Members of Australia's two largest osteopathy professional associations (i.e. Chiropractic and Osteopathic College of Australia; Osteopathy Australia) and an osteopathy practice-based research network (i.e. Osteopathy Research and Innovation Network [ORION]) were posted an invitation by email, with a reminder email posted 2 weeks later. Links to the survey were also disseminated via posts on social media, including the research team's Twitter, Instagram and LinkedIn accounts, as well as pertinent Facebook pages.

All recruitment materials provided a web-link to the subject information sheet and online survey, which was hosted by SurveyMonkey ${ }^{\text {mix }}$ (SurveyMonkey Inc., San Mateo, California, USA [www.surveymonkey.com]). Participants providing informed consent to participate (i.e. declaring that they met the eligibility criteria, understood what participation in the study involved, and understood what their rights were as a participant), were able to commence the survey. All survey items were made compulsory in order to mitigate the risk of missing data. The estimated completion time of the survey was 10-15 min. Data collection was undertaken between March 2018 and May 2018.

\section{Data analysis}

Survey data were imported into SPSS (v.25.0) for coding and statistical analysis. Surveys identified as being partially-complete (i.e. more than $20 \%$ of items were unanswered due to respondents dropping out of the survey) were excluded from the analysis [35]. Multiple responses from single participants were handled using the de-duplication method for online surveys as described by Konstan et al. [39]. All missing data were described as missing values. Frequency distributions and percentages were used to describe categorical data. For normally distributed descriptive data, means and standard deviations were used. For non-normally distributed descriptive data, medians and the interquartile range (IQR: which were reported as a range rather than a value) were used. Relationships between nominal-level variables were examined using Cramer's $\mathrm{V}$, and associations between ordinal-level variables 
assessed using Kendall's Tau correlation coefficient $(\mathrm{T})$. Coefficients between $0.10-0.29$ represented a weak correlation, $0.30-0.49$ a moderate correlation, and $0.50-1.00$ a strong correlation. Variables included in all tests of association were informed by previous studies using EBASE [30-35], and determined a priori. The significance threshold was set at $p<0.05$.

\section{Results}

A total of 368 Australian osteopaths completed the survey. Excluding multiple responses from single respondents $(n=2)$ and surveys with more than $20 \%$ unanswered items $(n=34)$, the adjusted sample size was 332 . This exceeded the minimum sample size required for the study. As the number of osteopaths receiving an invitation to participate could not be determined, it was not possible to report an exact survey response rate.

\section{Demographic characteristics}

Survey respondents were predominantly female (51.8\%), aged between 30 and 49 years (54.5\%) (Table 1). Most (59.6\%) held a Master's degree qualification, with the greatest proportion of respondents $(44 \%)$ receiving their highest qualification 11 or more years prior. Correspondingly, the majority $(48.8 \%)$ of respondents had practiced in the field of osteopathy for 11 or more years, with most $(66.2 \%)$ working $16-45 \mathrm{~h}$ a week in clinical practice. Few respondents participated in research $(0 \mathrm{~h} /$ week, $47.9 \%)$ or teaching in the higher education sector $(0 \mathrm{~h} /$ week, $71.1 \%)$.

Respondents worked in various clinical practice settings, with a slightly higher proportion (30.7\%) working in clinics with other CAM providers (Table 1). These practices were largely located in inner/outer city suburbs (58.7\%) within the Australian state of Victoria (45.5\%). The treatments typically provided by respondents in their first consultation with patients were diverse, with most using articulation (79.2\%), soft tissue therapy (74.1\%), and muscle energy therapy (72.3\%).

\section{Attitude toward EBP}

Respondents reported a median attitude subscore of 31 (IQR 27, 34; range 15-40), suggesting attitudes toward EBP were generally positive (with scores between 24.1 and 31.9 indicative of a predominantly neutral to agree response). In particular, respondents largely agreed that professional literature and research findings are useful for practice (83.4\%), and that EBP assists in clinical decision making $(86.7 \%)$, is necessary in the practice of osteopathy (84.6\%), improves the quality of patient care $(75.6 \%)$, and is fundamental to the advancement of the profession (73.2\%) (Table 2). The majority of respondents were also interested in learning or improving the skills necessary to incorporate EBP into practice, with $87.6 \%$ agreeing or strongly agreeing to this.
By contrast, many respondents disagreed/strongly disagreed that the adoption of EBP places an unreasonable demand on practice (59.9\%).

A weak negative association was observed between attitude subscore (categorised by quartiles) and years since receiving highest qualification $(T=-0.128, p=0.012)$. A weak positive association between attitude subscore and hours per week participating in research $(T=0.164, p=0.003)$ was also found. Associations between attitude subscore and other demographic characteristics were not shown to be statistically significant.

\section{Skills in EBP}

Respondents reported a median skills subscore of 40 (IQR 33, 46; range 15-65), signifying a mostly moderate level of perceived skill in EBP (with scores between 39.1 and 51.9 indicative of a predominantly moderate to somewhat high skill level). Relatively higher perceived skill levels were reported for items pertaining to the first stage of the EBP process (i.e. clinical problem identification). The lowest perceived skill levels were reported for items relating to advanced research activities, such as the conduct of systematic reviews and clinical research, with 72.9 and $83.7 \%$ of respondents, respectively, reporting low to lowmoderate skill levels for these tasks (Table 3).

Skill subscore (categorised by quartiles) was found to be weakly positively associated with age $(T=0.151, p=0.002)$, highest qualification $(T=0.120, p=0.022)$, hours per week teaching in the higher education sector $(T=0.231$, $p<0.001)$ and hours per week participating in research $(T=0.273, \quad p<0.001)$. Associations between skill subscore and other demographic characteristics were not found to be statistically significant.

\section{Utilisation of EBP}

Respondents reported a median use subscore of 7 (IQR 5, 11; range 0-24), representing a moderately-low level of engagement in EBP activities (with scores between 6.1 and 12.0 indicative of a moderately-low level of use). The majority (49.7-71.1\%) of respondents participated in EBP activities (i.e. the first six items) no more than five times in the previous month. Most respondents also engaged infrequently (i.e. $0-5$ times in the previous month) with the lay literature $(80.7 \%)$ or with colleagues/industry experts (66\%) (Table 4).

A weak positive association was observed between use subscore (categorised by quartiles) and highest qualification ( $\mathcal{T}=0.119, p=0.022$ ), hours per week teaching in the higher education sector $(T=0.194, p<0.001)$ and hours per week participating in research $(T=0.250, p<0.001)$. There was also a weak negative association between use subscore and years since receiving highest qualification $(T=-0.112$, $p=0.034$ ). Associations between use subscore and other demographic characteristics were not shown to be statistically significant. 
Table 1 Demographic characteristics of sample $(n=332)$

\begin{tabular}{l} 
Characteristic \\
\hline Age, $n$ (\%) \\
20-29years \\
30-39years \\
40-49 years \\
50-59 years \\
60-69years \\
70+ years \\
Missing \\
Sex, $n$ (\%) \\
Female \\
Male \\
Other \\
Missing \\
Highest qualification, $n$ (\%) \\
Diploma/Advanced Diploma \\
Bachelor degree \\
Honours degree \\
Graduate Certificate/Diploma \\
Master's degree \\
PhD/Professional doctorate \\
Missing
\end{tabular}

Years since receiving highest qualification, $n$ (\%)

$$
\begin{aligned}
& <1 \text { year } \\
& 1-5 \text { years } \\
& 6-10 \text { years } \\
& 11-15 \text { years } \\
& 16+\text { years } \\
& \text { Missing }
\end{aligned}
$$

Years practiced in the field of osteopathy, $n$ (\%)

$$
\begin{aligned}
& <1 \text { year } \\
& 1-5 \text { years } \\
& 6-10 \text { years } \\
& 11-15 \text { years } \\
& 16+\text { years } \\
& \text { Missing }
\end{aligned}
$$

Hours per week in clinical (osteopathic) practice, $n$ (\%)

$$
\begin{aligned}
& \text { Oh } \\
& 1-15 h \\
& 16-30 h \\
& 31-45 h \\
& 46+\text { hours } \\
& \text { Missing }
\end{aligned}
$$

Hours per week participating in research, $n$ (\%)
Frequency

$52(15.7)$

109 (32.8)

$72(21.7)$

$39(11.7)$

$13(3.9)$

2 (0.6)

45 (13.6)

$172(51.8)$

$113(34.0)$

2 (0.6)

45 (13.6)

$11(3.3)$

50 (15.1)

$11(3.3)$

$12(3.6)$

$198(59.6)$

$5(1.5)$

$45(13.6)$

$14(4.2)$

$63(19.0)$

64 (19.3)

69 (20.8)

77 (23.2)

45 (13.6)

$10(3.0)$

49 (14.8)

66 (19.9)

64 (19.3)

98 (29.5)

45 (13.6)

$2(0.6)$

$43(13.0)$

$108(32.5)$

$112(33.7)$

$22(6.6)$

45 (13.6)

$159(47.9)$
Table 1 Demographic characteristics of sample $(n=332)$

(Continued)

\begin{tabular}{ll}
\hline Characteristic & Frequency \\
\hline $1-15 h$ & $121(36.5)$ \\
$16-30 h$ & $4(1.2)$ \\
$31-45 h$ & $1(0.3)$ \\
$46+$ hours & $1(0.3)$ \\
Missing & $46(13.9)$
\end{tabular}

Hours per week teaching in the higher education sector, $n$ (\%)

oh

$236(71.1)$

$1-15 h$

41 (12.4)

16-30h

8 (2.4)

$31-45 h$

$1(0.3)$

$46+$ hours

$0(0.0)$

Missing

46 (13.9)

Treatments typically provided in first osteopathic consultation, $n$ (\%)

Articulation

263 (79.2)

Soft tissue therapy

246 (74.1)

Muscle energy therapy

$240(72.3)$

HVLA thrust

$212(63.9)$

Exercise

209 (63.0)

General osteopathic treatment 185 (55.7)

Myofascial release

$181(54.5)$

Strain-counterstrain

$160(48.2)$

Functional technique

$112(33.7)$

Relaxation advice

$104(31.3)$

Cranial technique

$77(23.2)$

Other

$70(21.1)$

Visceral therapy

$57(17.2)$

Acupuncture/acupressure $\quad 26(7.8)$

Ice/cold treatment $24(7.2)$

Orthotics 6 (1.8)

Electrotherapy 5 (1.5)

Steroid injection $1(0.3)$

Clinical setting in which osteopathy was predominantly practiced, $n$ (\%)

With a group of CAM providers

$102(30.7)$

Solo practice

$76(22.9)$

With a group of conventional providers

69 (20.8)

With CAM \& conventional providers

34 (10.2)

Within an educational institution

$3(0.9)$

Missing

$48(14.5)$

Geographical location, $n$ (\%)

Victoria

$151(45.5)$

New South Wales

$78(23.5)$

Queensland

$27(8.1)$

Tasmania

13 (3.9) 
Table 1 Demographic characteristics of sample $(n=332)$ (Continued)

\begin{tabular}{ll}
\hline Characteristic & Frequency \\
\hline Western Australia & $7(2.1)$ \\
South Australia & $5(1.5)$ \\
Australian Capital Territory & $2(0.6)$ \\
Northern Territory & $1(0.3)$ \\
Missing & $48(14.5)$ \\
Osteopathy professional association membership, n (\%) & \\
Osteopathy Australia & $268(80.7)$ \\
Not a member of an Osteopathy professional association & $9(2.7)$ \\
Chiropractic and Osteopathic College of Australasia & $4(1.2)$ \\
Other & $2(0.6)$ \\
Missing & $49(14.8)$ \\
Geographical region, $n$ (\%) & \\
Inner city suburbs & $107(32.2)$ \\
Outer city suburbs & $88(26.5)$ \\
Rural/remote region & $58(17.5)$ \\
City (Central business district) & $26(7.8)$ \\
Missing & $53(16.0)$ \\
\hline CAM Complen
\end{tabular}

CAM Complementary and alternative medicine, HVLA high-velocity low amplitude
Most respondents indicated that a very small (1$25 \%$ of practice; $28.6 \%)$ or small $(26-50 \%$ of practice, 28.6\%) proportion of their clinical practice was based on clinical research evidence. Those reporting a moderate $(51-75 \%$ of practice) or large (76-99\%) proportion of their practice as being based on clinical research evidence represented 25.9 and $7.8 \%$ of respondents, respectively. Few respondents indicated that none $(1.8 \%)$ or all of their practice $(0.9 \%)$ was informed by evidence from clinical trials. Traditional knowledge was the highest ranked information source (median rank 3; IQR 1, 6) used by respondents to inform clinical decision making. This was followed by clinical practice guidelines (median rank 3; IQR 3, 6) and consultation with fellow practitioners or experts (median rank 4; IQR 3, 6) (Table 5).

\section{Training in EBP}

The majority of respondents had undertaken some degree of training in evidence-based practice/osteopathy (88.3\%), evidence application (78.9\%), critical thinking/ analysis $(76.8 \%)$, and clinical research $(61.8 \%)$, and to a lesser extent, the conduct of systematic reviews and meta-analyses (53.9\%). In most cases, this training was completed as a minor (27.4-32.2\%) or major (9.6-29.5\%) component of a study program.

Table 2 Respondent attitudes toward evidence-based practice $(n=332)$

\begin{tabular}{|c|c|c|c|c|c|c|}
\hline & 1 & 2 & 3 & 4 & 5 & Median \\
\hline & $\begin{array}{l}\text { Strongly Disagree } \\
n(\%)\end{array}$ & $\begin{array}{l}\text { Disagree } \\
n(\%)\end{array}$ & $\begin{array}{l}\text { Neutral } \\
n(\%)\end{array}$ & $\begin{array}{l}\text { Agree } \\
n(\%)\end{array}$ & $\begin{array}{l}\text { Strongly Agree } \\
n(\%)\end{array}$ & \\
\hline $\begin{array}{l}\text { Professional literature (i.e. journals \& textbooks) } \\
\text { and research findings are useful in my day-to-day } \\
\text { practice }\end{array}$ & $3(0.9)$ & $21(6.3)$ & $31(9.3)$ & $194(58.4)$ & $83(25.0)$ & $4(4,5)$ \\
\hline $\begin{array}{l}\text { EBP assists me in making decisions about } \\
\text { patient care }\end{array}$ & $1(0.3)$ & $17(5.1)$ & $26(7.8)$ & $188(56.6)$ & $100(30.1)$ & $4(4,5)$ \\
\hline $\begin{array}{l}\text { I am interested in learning or improving the } \\
\text { skills necessary to incorporate EBP into my } \\
\text { practice }\end{array}$ & $1(0.3)$ & $13(3.9)$ & $27(8.1)$ & $168(50.6)$ & $123(37.0)$ & $4(4,5)$ \\
\hline EBP is necessary in the practice of osteopathy & $4(1.2)$ & $14(4.2)$ & $33(9.9)$ & $164(49.4)$ & $117(35.2)$ & $4(4,5)$ \\
\hline EBP improves the quality of my patient's care & $2(0.6)$ & $30(9.0)$ & $49(14.8)$ & $151(45.5)$ & $100(30.1)$ & $4(4,5)$ \\
\hline $\begin{array}{l}\text { There is a lack of evidence from clinical trials } \\
\text { to support most of the treatments I use in } \\
\text { my practice }\end{array}$ & $10(3.0)$ & $64(19.3)$ & $74(22.3)$ & $142(42.8)$ & $42(12.7)$ & $4(3,4)$ \\
\hline $\begin{array}{l}\text { Prioritizing EBP within osteopathic practice } \\
\text { is fundamental to the advancement of the } \\
\text { profession }\end{array}$ & $9(2.7)$ & $32(9.6)$ & $48(14.5)$ & $141(42.5)$ & $102(30.7)$ & $4(3,5)$ \\
\hline $\begin{array}{l}\text { EBP takes into account my clinical experience } \\
\text { when making clinical decisions }\end{array}$ & $12(3.6)$ & $83(25.0)$ & 64 (19.3) & $115(34.6)$ & $58(17.5)$ & $4(2,4)$ \\
\hline $\begin{array}{l}\text { EBP takes into account a patient's preference } \\
\text { for treatment }\end{array}$ & $21(6.3)$ & 110 & $81(24.4)$ & $90(27.1)$ & $30(9.0)$ & $3(2,4)$ \\
\hline $\begin{array}{l}\text { The adoption of EBP places an unreasonable } \\
\text { demand on my practice }\end{array}$ & $36(10.8)$ & $163(49.1)$ & 76 (22.9) & 49 (14.8) & $8(2.4)$ & $2(2,3)$ \\
\hline
\end{tabular}

EBP Evidence-based practice, IQR Interquartile range 
Table 3 Respondent self-reported skills in evidence-based practice $(n=332)$

\begin{tabular}{|c|c|c|c|c|c|c|}
\hline & \multirow{2}{*}{$\begin{array}{l}1 \\
\text { Low } \\
n(\%)\end{array}$} & \multirow{2}{*}{$\begin{array}{l}2 \\
\text { Low-moderate } \\
n(\%)\end{array}$} & \multirow{2}{*}{$\begin{array}{l}3 \\
\text { Moderate } \\
n(\%)\end{array}$} & \multirow{2}{*}{$\begin{array}{l}4 \\
\text { Moderate-high } \\
n(\%)\end{array}$} & \multirow{2}{*}{$\begin{array}{l}5 \\
\text { High } \\
n(\%)\end{array}$} & \multirow{2}{*}{$\begin{array}{l}\text { Median } \\
(\mathrm{IQR})\end{array}$} \\
\hline & & & & & & \\
\hline Identifying precise clinical questions & $8(2.4)$ & $29(8.7)$ & $127(38.3)$ & $131(39.5)$ & $37(11.1)$ & $4(3,4)$ \\
\hline Identifying knowledge gaps in practice & $5(1.5)$ & $20(6.0)$ & $128(38.6)$ & $130(39.2)$ & $49(14.8)$ & $4(3,4)$ \\
\hline Locating professional literature & $16(4.8)$ & $56(16.9)$ & $85(25.6)$ & $99(29.8)$ & $76(22.9)$ & $4(3,4)$ \\
\hline Online database searching & $28(8.4)$ & 45 (13.6) & $90(27.1)$ & $93(28.0)$ & $76(22.9)$ & $4(3,4)$ \\
\hline Retrieving evidence & $26(7.8)$ & $52(15.7)$ & $102(30.7)$ & $94(28.3)$ & $58(17.5)$ & $3(3,4)$ \\
\hline Critical appraisal of evidence & $26(7.8)$ & $54(16.3)$ & $109(32.8)$ & $109(32.8)$ & $34(10.2)$ & $3(3,4)$ \\
\hline Synthesis of research evidence & $37(11.1)$ & $83(25.0)$ & $110(33.1)$ & $79(23.8)$ & $23(6.9)$ & $3(2,4)$ \\
\hline Applying research evidence to patient cases & $16(4.8)$ & $40(12.0)$ & $115(34.6)$ & $128(38.6)$ & $33(9.9)$ & $3(3,4)$ \\
\hline Sharing evidence with colleagues & $27(8.1)$ & $71(21.4)$ & $103(31.0)$ & $86(25.9)$ & 45 (13.6) & $3(2,4)$ \\
\hline Using findings from clinical research & $12(3.6)$ & $45(13.6)$ & $129(38.9)$ & $123(37.0)$ & $23(6.9)$ & $3(3,4)$ \\
\hline Using findings from systematic reviews & $41(12.3)$ & $73(22.0)$ & $108(32.5)$ & $81(24.4)$ & $29(8.7)$ & $3(2,4)$ \\
\hline Conducting systematic reviews & $151(45.5)$ & $91(27.4)$ & $64(19.3)$ & $17(5.1)$ & $9(2.7)$ & $2(1,3)$ \\
\hline Conducting clinical research & $202(60.8)$ & $76(22.9)$ & $33(9.9)$ & $18(5.4)$ & $3(0.9)$ & $1(1,2)$ \\
\hline
\end{tabular}

IQR Interquartile range

Table 4 Participant use of evidence-based practice (i.e. number of times each activity was undertaken within the last month) $(n=332)$

\begin{tabular}{|c|c|c|c|c|c|c|c|}
\hline & 0 & 1 & 2 & 3 & 4 & \multirow{2}{*}{$\begin{array}{l}\text { Missing } \\
n(\%)\end{array}$} & \multirow{2}{*}{$\begin{array}{l}\text { Median } \\
\text { (IQR) }\end{array}$} \\
\hline & $\begin{array}{l}0 \\
\text { times } \\
n(\%)\end{array}$ & $\begin{array}{l}1-5 \\
\text { times } \\
n(\%)\end{array}$ & $\begin{array}{l}6-10 \\
\text { times } \\
n(\%)\end{array}$ & $\begin{array}{l}11-15 \\
\text { times } \\
n(\%)\end{array}$ & $\begin{array}{l}16+ \\
\text { times } \\
n(\%)\end{array}$ & & \\
\hline $\begin{array}{l}\text { I have read/reviewed professional } \\
\text { literature (i.e. professional journals } \\
\text { \& textbooks) related to my practice }\end{array}$ & $53(16.0)$ & $159(47.9)$ & 49 (14.8) & $25(7.5)$ & $33(9.9)$ & $13(3.9)$ & $1(1,2)$ \\
\hline $\begin{array}{l}\text { I have read/reviewed clinical research } \\
\text { findings related to my practice }\end{array}$ & 66 (19.9) & $170(51.2)$ & $42(12.7)$ & $14(4.2)$ & $27(8.1)$ & $13(3.9)$ & $1(1,2)$ \\
\hline $\begin{array}{l}\text { I have used professional literature } \\
\text { or research findings to assist my } \\
\text { clinical decision-making }\end{array}$ & $43(13.0)$ & 168 (50.6) & $47(14.2)$ & $22(6.6)$ & $39(11.7)$ & $13(3.9)$ & $1(1,2)$ \\
\hline $\begin{array}{l}\text { I have used an online database } \\
\text { to search for practice related } \\
\text { literature or research }\end{array}$ & $112(33.7)$ & $124(37.3)$ & $31(9.3)$ & $21(6.3)$ & $27(8.1)$ & $17(5.1)$ & $1(0,2)$ \\
\hline $\begin{array}{l}\text { I have used professional literature } \\
\text { or research findings to change } \\
\text { my clinical practice }\end{array}$ & 85 (25.6) & 177 (53.3) & $27(8.1)$ & $14(4.2)$ & $16(4.8)$ & $13(3.9)$ & $1(0,1)$ \\
\hline $\begin{array}{l}\text { I have used an online search engine } \\
\text { to search for practice related } \\
\text { literature or research }\end{array}$ & $21(6.3)$ & $144(43.4)$ & $67(20.2)$ & $30(9.0)$ & $53(16.0)$ & $17(5.1)$ & $1(1,3)$ \\
\hline $\begin{array}{l}\text { I have consulted a colleague } \\
\text { or industry expert to assist } \\
\text { my clinical decision-making }\end{array}$ & 49 (14.8) & $170(51.2)$ & $58(17.5)$ & $18(5.4)$ & $20(6.0)$ & $17(5.1)$ & $1(1,2)$ \\
\hline $\begin{array}{l}\text { I have referred to magazines, } \\
\text { layperson / self-help books, } \\
\text { or non-government/non- } \\
\text { education institution websites } \\
\text { to assist my clinical decision-making }\end{array}$ & 115 (34.6) & $153(46.1)$ & $31(9.3)$ & $5(1.5)$ & $11(3.3)$ & $17(5.1)$ & $1(0,1)$ \\
\hline
\end{tabular}


Table 5 Sources of information used to inform clinical decisionmaking (ranked by most frequent to least frequently used source $)^{\text {a }}(n=332)$

\begin{tabular}{ll}
\hline Information source & Median (IQR) \\
\hline Traditional knowledge & $3(1,6)$ \\
Clinical practice guidelines & $3(2,6)$ \\
Consulting fellow practitioners or experts & $4(3,6)$ \\
Published clinical evidence (i.e. clinical trials) & $5(2,8)$ \\
Textbooks & $5(3,7)$ \\
Personal intuition & $5(3,8)$ \\
Patient preference & $6(4,8)$ \\
Personal preference & $6(4,8)$ \\
Trial and error & $8(6,9)$ \\
Published experimental/laboratory evidence & $9(6,10)$ \\
\hline
\end{tabular}

$I Q R$ Interquartile range

${ }^{\text {a }}$ Sources were ranked from $1=$ most frequently used, to $10=$ least frequently used

\section{Barriers to and enablers of EBP uptake}

Respondents reported few barriers to the uptake of EBP in osteopathy, with 11 of 13 listed factors (i.e. lack of resources, skills in the location/interpretation/appraisal/ application of evidence, incentive, interest, relevance, colleague/industry support, patient preference) being perceived as either not a barrier, or only a minor barrier to EBP uptake. The only factors identified as 'moderate' or 'major' barriers to EBP uptake were lack of clinical evidence in osteopathy (59.9\%), and lack of time (52.7\%).

Most respondents indicated that the 10 listed enabling factors facilitated the uptake of EBP in osteopathy, albeit with varying levels of perceived usefulness. Enablers considered to be 'very useful' by most participants were improving access to the internet in the workplace (69.6\%), online EBP education materials $(63.6 \%)$, free online databases $(62.3 \%)$, databases requiring licence fees $(57.2 \%)$ and critical reviews of research evidence relating to osteopathy (50.6\%), as well as the ability to download full-text articles (63.0\%). Among enablers perceived to be 'moderately to very useful' were access to critically appraised topics relating to osteopathy $(69.9 \%)$, critical appraisal tools $(60.5 \%)$ and research rating tools (58.7\%), and online tools that facilitate practitioner appraisal of the evidence (51.5\%).

\section{Discussion}

This study has revealed some important insights into Australian osteopaths' attitudes, skills and utilisation of evidence-based practice, as well as the barriers and enablers of EBP uptake among this professional group. Australian osteopaths were generally supportive of EBP, but largely reported low levels of EBP uptake in clinical practice. Further, despite most respondents completing some form of EBPrelated training, perceived EBP skill levels were generally modest. Understanding the implications of these and other identified barriers and enablers of evidence-based practice uptake is a logical next step of this research, and consequently, is the focus of this discussion.

\section{EBP skills}

Encouragingly, respondents reported positive attitudes to the role of EBP in osteopathic practice. They also reported moderate-to-high levels of self-perceived skill in the identification of clinical questions and knowledge gaps in practice, as well as appraising and applying evidence from research to their clinical practice. These findings were similar to the perceived EBP skill level reported by UK osteopaths [29]. Interestingly, respondents in the current study judged their skills in the relatively high-level tasks of 'critical appraisal' and 'evidence synthesis' to be of similar level as the more fundamental skill of 'using findings from systematic reviews'. Notwithstanding, it should be emphasised that these surveys reported self-perceived skill in EBP and did not measure the actual skill level of respondents. It is possible that respondents who lack comprehensive knowledge of EBP could have over-estimated their skill level [40].

The lowest perceived skill levels relating to EBP were reported for the conduct of clinical research and/or systematic reviews. Given that this survey was distributed to practicing osteopaths, most without academic or research affiliations, it should be expected that they use research findings rather than produce them. Again, our findings are similar to recent studies, where Malaysian physiotherapists [41], US chiropractors [32] and UK osteopaths [29] were found to be confident in information appraisal, but lacked research skills. The small percentage of osteopaths reporting high-level skill in conducting clinical research or systematic reviews was also similar to previous studies of US and Canadian chiropractors where less than $5 \%$ of respondents reported a high level of skill in these areas [31,32]. Although allied health professionals should not necessarily be responsible for conducting research or literature reviews [42], we would expect that osteopaths should be able to search for and apply findings from systematic reviews and evidencebased guidelines to their daily practice. This ability is unlikely to represent a major barrier to EBP uptake amongst Australian osteopaths, with respondents reporting moderate to moderate-high level skills in these areas.

\section{Use of EBP}

Despite the favourable view of EBP and moderately-high level of perceived skills in EBP, the majority of respondents reported low levels of engagement in evidencebased practice activities (i.e. they participated in these activities no more than five times in the previous month). Surprisingly, over a quarter of respondents reported that they never used an online database to search 
for practice-related literature or used this literature to change clinical practice over the last month. Similarly, about $20 \%$ of respondents reported that they never read or reviewed clinical research findings related to practice in the previous month. Instead, only around $15 \%$ of respondents regularly reviewed clinical research findings, searched online databases or used professional literature to assist in daily clinical decision-making. Adding to this, nearly $60 \%$ of respondents reported very small/small proportions of their clinical practice to be based on EBP.

Most respondents relied upon traditional knowledge, clinical practice guidelines and fellow professionals to inform their clinical decision making. What is not clear is whether this dependency on traditional knowledge in Australian osteopathic practice is largely a 'capacity' issue (i.e. insufficient scientific evidence in the field, lack of time or sufficient skill to engage in EBP), a more entrenched 'cultural' issue (i.e. widespread disinterest in research, perception that the effectiveness of osteopathy is not amenable to scientific testing), or a product of both of these factors, or something entirely different [43]. Regardless of the reason, keeping up-to-date with current research, not in place of but as a complement to other relevant strategies, must be considered an important aspect of clinical practice in contemporary osteopathy. Thus, strategies and initiatives to increase EBP engagement in osteopathy practice may be important topics for future research.

Although the findings of the current study, and those of our recent UK study [29] indicate that Australian and UK osteopaths engage in EBP activities to a similar extent, the level of engagement in EBP appears to be somewhat lower than other manual therapy professions. In analogous studies involving chiropractors in the US [32] and Canada [31] (both of which used EBASE), approximately one-third of chiropractors reported reviewing professional literature / clinical research findings related to their practice, and using online search engines to search for practice-related literature, more than 11 times in the previous month [32]. By contrast, less than one-fifth of Australian and UK osteopaths engaged in the same activities to the same extent [29].

A possible explanation for the relatively low frequency of EBP activity among Australian and UK osteopaths may relate to the presentation of patients with a consistent range of symptoms and disorders that do not require frequent searching of evidence. However, if that were the case, one might expect chiropractors, and possibly physical therapists, to see a similar patient population. Yet, both chiropractors [31,32] and physical therapists [44] report relatively higher levels of engagement in EBP activities. In one study of US physical therapists, $66 \%$ of respondents reported consulting research material and $52 \%$ having used a medical database, four to ten times weekly to make clinical practice decisions [44]. While a heterogeneous patient population might represent a probable reason for the differences in EBP utilisation between osteopaths and other manual therapists, other factors are equally possible, including differences in the level of research/EBP training, culture and opportunities for engagement [45].

\section{Barriers to EBP uptake}

Given the positive attitude to evidence-based practice, but the low level of EBP utilisation among respondents, an examination of the barriers to EBP uptake should be revealing. However, participants perceived 11 of the 13 listed barriers to EBP as being only a minor barrier or not a barrier to EBP at all. The only factors identified as moderate or major barriers to EBP uptake were lack of clinical evidence in osteopathy and lack of time.

It is true that there is a lack of osteopathy-specific clinical research for both common and uncommon conditions treated by osteopaths; and while clinical evidence for osteopathic manipulative therapy is now emerging, methodological rigour is often lacking [46]. However, there is still much research in related disciplinary areas (e.g. physiotherapy, occupational therapy, chiropractic) that may be used to inform osteopathy practice $[47,48]$. Thus, it is possible that the perceived 'lack of clinical evidence' was identified as a barrier to EBP uptake due to a poor understanding of the nature and activities of EBP. This level of understanding may stem from insufficient training in EBP, with the majority of respondents reporting some training in evidence-based practice, which was typically undertaken as a minor component of a professional study program. Although there have been calls to improve the development of EBP skills in osteopathy programs [49], it is likely the training offered over the last two decades has been variable and inadequate - particularly programs delivered more than 10 years ago.

Lack of time is not only a major barrier to EBP uptake reported by osteopaths [29], but also by nurses [50, 51], physiotherapists [44, 52, 53], chiropractors [31, 32, 54, 55] and other clinicians $[56,57]$. However, some academics have argued that time is merely an excuse for not changing practice, and that clinicians playing the lack of time card' simply do not value EBP [58]. The same academics argue that these clinicians instead need some buy-in [58]. Indeed, studies of practicing chiropractors in the US, Canada, Australia and the UK indicate that lack of incentive is a notable barrier to EBP uptake [31, 32, 54, 55]. What is not clear at this point in time however, is whether incentivisation effectively improves EBP uptake, which of course should be a focus of further enquiry.

\section{Enablers of EBP uptake}

Australian osteopaths agreed that research findings are useful for practice, and that EBP assists in clinical 
decision making and is necessary in the practice of osteopathy. The majority of respondents also identified themselves as having a moderate or moderate-high level of EBP skills. Despite this, the reported frequency of EBP activity was low. In the absence of many identified barriers to EBP beyond relevant evidence and time constraints, the perceived enablers of EBP may provide useful insights on how to promote greater uptake of EBP in osteopathy.

Two factors perceived by respondents as being particularly helpful in enabling EBP uptake in osteopathy practice were accessibility of evidence (i.e. access to the internet, databases and full-text articles in the workplace) and access to EBP training (particularly online EBP education materials). These enabling strategies were consistent with those reported by UK osteopaths [29] and Canadian chiropractors [31]. However, internet connectivity in the workplace is now largely ubiquitous, and primary online medical databases, such as PubMed, PEDro and The Cochrane Library, are free to access (at least in Australia) and include many open access fulltext articles. Further, 90\% of registered Australian osteopaths are members of the main osteopathic professional body [59], which provides members with access to fulltext articles through various databases and journals. It is therefore unlikely that further efforts to expand clinician access to online resources would greatly enhance EBP uptake. Instead, the Australian osteopathy profession should consider placing emphasis on continuing profession education in EBP as a more suitable approach to improve the adoption of EBP within the osteopathic workforce. At present, there are no requirements for registered osteopaths (at least in Australia) to undertake continuing education in EBP.

\section{Limitations}

While it is not possible to accurately determine the response rate to this survey due to the nature of sampling/ recruitment, the survey appeared to be completed by approximately 14.6\% (332/2277) of Australian osteopaths. This not only exceeded the minimum sample size required for this study, but also the response rates for other EBP surveys involving complementary medicine disciplines, including Canadian chiropractors (8\%) [31], UK osteopaths (7.2\%) [29], US yoga therapists (7.1\%) [35] and US chiropractors (2.2\%) [32]. Notwithstanding, there are some limitations to this study that are worth noting. As with any survey examining attitudes, it is possible that participants with an interest in EBP might have been more likely to participate in this study, which may have inadvertently introduced some degree of selection bias. In the event that selection bias was present, it is probable that participant attitudes to EBP may be generally more positive than that reported across the osteopathy profession, and that the level of engagement in EBP activities may be less frequent. However, as the demographic profile of participants closely approximated the age, sex, geographical distribution, type of practice setting and highest qualification of Australian osteopaths, it is probable that the study sample was broadly representative of the Australian osteopathy workforce [2]. Other limitations inherent in the survey design include the reliance on self-reported information and recall bias. Additionally, perceived skill level can be tainted by cognitive bias, particularly among participants with lowlevel knowledge and skill, which may result in overestimation of such knowledge and skill (referred to as the Dunning-Kruger effect) [40].

The above limitations, as well as the understandings gained from this study, highlight the need for further research in this field. For instance, there is a need to investigate the skill/competency level of osteopaths with regards to applying EBP, and to better understand the skills that are required for the successful integration of EBP into osteopathic practice. A related area of research is the development, implementation and evaluation of appropriate interventions that facilitate the uptake of EBP by the osteopathy workforce. Such work could be facilitated through improved collaboration between professional, educational and academic research bodies, as has already been demonstrated through the recent Osteopathy Research and Innovation Network (ORION) project [3].

\section{Conclusions}

This study has revealed important insights into Australian osteopath attitudes, skills and utilisation of EBP. Overall, respondents were generally positive toward EBP, and the majority agreed or strongly agreed that EBP assists in making clinical decisions, improves the quality of patient care, and is necessary in the practice of osteopathy. Despite the majority of respondents reporting a moderate or moderately-high level of EBP skills, the level of engagement in EBP activities over the preceding month was low. Principle barriers to EBP were identified as lack of time and a paucity of clinical evidence in osteopathy. The main enablers of EBP uptake related to improving access to evidence and training in EBP. The findings suggest that continuing professional education initiatives in EBP may be valuable in assisting osteopaths to more frequently engage in EBP activities in clinical practice.

\section{Abbreviations \\ CAM: Complementary and alternative medicine; EBASE: Evidence-Based practice Attitude and utilization SurvEy; EBP: Evidence-based practice; HVLA: High-velocity low amplitude; IQR: Interquartile range}

\section{Acknowledgements}

The authors would like to thank the Australian Osteopathy Research and Innovation Network (ORION), Osteopathy Australia (OA) and the Chiropractic and Osteopathic College of Australasia (COCA) for promoting the survey and distributing invitations to their respective members. 


\section{Authors' contributions}

$\mathrm{ML}$ and TS conceived the study. ML analysed the data, and drafted the methods and results. OT and TS drafted the background. GF and PA drafted the discussion. JA reviewed and contributed to all sections of the paper. All authors critically reviewed, edited and approved the final manuscript.

\section{Funding}

The study did not receive any financial support from any sponsor.

\section{Availability of data and materials}

The datasets used and/or analysed during the current study are available from the corresponding author on reasonable request.

\section{Ethics approval and consent to participate}

The study was approved by the University of South Australia Human Research Ethics Committee. All participants were provided with a detailed study information sheet, with completion of the survey implying consent. Participation in the study was voluntary, and participants had the right to withdraw from the study at any time without repercussion. Survey data were non-identifiable in order to maintain participant anonymity.

\section{Consent for publication}

Not applicable.

\section{Competing interests}

The authors declare that they have no competing interests.

\section{Author details}

${ }^{1}$ Department of Rural Health, University of South Australia, Adelaide, Australia. ${ }^{2}$ Australian Research Centre in Complementary and Integrative Medicine (ARCCIM), Faculty of Health, University of Technology Sydney, Sydney, NSW, Australia. ${ }^{3}$ Musculoskeletal and Sports Injury Epidemiology Center (MUSIC), Institute of Environmental Medicine, Karolinska Institutet, Stockholm, Sweden. ${ }^{4}$ College of Health \& Biomedicine, Victoria University, Melbourne, Victoria, Australia. ${ }^{5}$ Department of Pain Management, Greenwich Hospital, Sydney, Australia. ${ }^{6}$ University College of Osteopathy, London, United Kingdom. ${ }^{7}$ Clinical-based Human Research Department, Centre for Osteopathic Medicine Collaboration (COME), Pescara, Italy.

\section{Received: 19 February 2019 Accepted: 8 July 2019}

Published online: 17 July 2019

\section{References}

1. Osteopathic International Alliance. Defining the Profession. 2018. https:// oialliance.org/about-us/osteopathic-medicine-and-osteopathy/. Accessed 17 Dec 2018.

2. Osteopathy Board of Australia (OBA). Osteopathy Board of Australia registrant data: reporting period 1 January 2018-31 March 2018. Melbourne: Osteopathy Board of Australia; 2018.

3. Adams J, Sibbritt D, Steel A, Peng W. A workforce survey of Australian osteopathy: analysis of a nationally-representative sample of osteopaths from the osteopathy research and innovation network (ORION) project. BMC Health Serv Res. 2018;18:352.

4. Osteopathic International Alliance. A global view of practice, patients, education and the contribution to healthcare delivery. 2014. http:// oialliance.org/resources/oia-status-report/. Accessed 17 Dec 2018.

5. Johnson SM, Kurtz ME. Diminished use of osteopathic manipulative treatment and its impact on the uniqueness of the osteopathic profession. Acad Med. 2001;76:821-8.

6. Burke SR, Myers R, Zhang AL. A profile of osteopathic practice in Australia 2010-2011: a cross sectional survey. BMC Musculoskelet Disord. 2013;14:227.

7. Fawkes C, Leach C, Mathias S, Moore A. A profile of osteopathic care in private practices in the United Kingdom: a national pilot using standardised data collection. Man Ther. 2014;19:125-30.

8. Orrock P. Profile of members of the Australian osteopathic association: part 1 - the practitioners. Int J Osteopath Med. 2009;12:14-24.

9. Thomson OP, Petty NJ, Moore AP. Osteopaths' professional views, identities and conceptions - a qualitative grounded theory study. Int J Osteopath Med. 2014;17:146-59.
10. Blaich R, Steel A, Clark D, Adams J. Challenges and opportunities for Australian osteopathy: a qualitative study of the perceptions of registered osteopaths. Int J Osteopath Med. 2018;30:18-24.

11. Clarkson HJ, Thomson OP. 'Sometimes I don't feel like an osteopath at all' a qualitative study of final year osteopathy students' professional identities. Int J Osteopath Med. 2017;26:18-27.

12. Kasiri-Martino H, Bright P. Osteopathic educators' attitudes towards osteopathic principles and their application in clinical practice: a qualitative inquiry. Man Ther. 2016;21:233-40.

13. Thomson OP, Petty NJ, Moore AP. Clinical decision-making and therapeutic approaches in osteopathy-a qualitative grounded theory study. Man Ther. 2014;19:44-51.

14. Thomson OP, Petty NJ, Moore AP. A qualitative grounded theory study of the conceptions of clinical practice in osteopathy-a continuum from technical rationality to professional artistry. Man Ther. 2014;19:37-43.

15. Licciardone JC. Osteopathic research: elephants, enigmas, and evidence. Osteopath Med Prim Care. 2007;1:7.

16. Licciardone JC. Time for the osteopathic profession to take the lead in musculoskeletal research. Osteopath Med Prim Care. 2009;3:6.

17. Steel A, Blaich R, Sundberg T, Adams J. The role of osteopathy in clinical care: broadening the evidence-base. Int J Osteopath Med. 2017;24:32-6.

18. Vogel S. Evidence, theory and variability in osteopathic practice. Int J Osteopath Med. 2015;18:1-4

19. Fryer G. Teaching critical thinking in osteopathy-integrating craft knowledge and evidence-informed approaches. Int J Osteopath Med. 2008:11:56-61.

20. Evidence-based medicine working group. Evidence-based medicine. A new approach to teaching the practice of medicine. J Am Med Assoc. 1992;268:2420.

21. Sackett DL. Evidence-based medicine. Semin Perinatol. 1997;21:3-5.

22. Greenhalgh T. Of lamp posts, keys, and fabled drunkards: a perspectival tale of 4 guidelines. J Eval Clin Pract. 2018;24:1132-8.

23. Greenhalgh T, Howick J, Maskrey N. Evidence based medicine: a movement in crisis? Br Med J. 2014;348:g3725.

24. Weber V, Rajendran D. UK trained osteopaths' relationship to evidence based practice-an analysis of influencing factors. Int J Osteopath Med. 2018; 29:15-25.

25. Figg-Latham J, Rajendran D. Quiet dissent: the attitudes, beliefs and behaviours of UK osteopaths who reject low back pain guidance-a qualitative study. Musculoskelet Sci Pract. 2017;27:97-105.

26. Inman J, Thomson OP. Complementing or conflicting? A qualitative study of osteopaths' perceptions of NICE low back pain and sciatica guidelines in the UK. Int J Osteopath Med. 2019;31:7-14.

27. Grace $S$, Engel R, Jalsion I. Themes underlying Australian general practitioner views towards chiropractic and osteopathy: an assessment of free text data from a cross-sectional survey. Evid Based Complement Alternat Med. 2018;2018:2786106.

28. Engel RM, Beirman R, Grace S. An indication of current views of Australian general practitioners towards chiropractic and osteopathy: a cross-sectional study. Chiropr Man Therap. 2016;24:37.

29. Sundberg T, Leach MJ, Thomson OP, Austin P, Fryer G, Adams J. Attitudes, skills and use of evidence-based practice among UK osteopaths: a national cross-sectional survey. BMC Musculoskelet Disord. 2018;19:439.

30. Alcantara J, Leach MJ. Chiropractic attitudes and utilization of evidencebased practice: the use of the EBASE questionnaire. EXPLORE. 2015;11: $367-76$.

31. Bussières $A E$, Terhorst $L$, Leach $M$, Stuber $K$, Evans $R$, Schneider MJ. Selfreported attitudes, skills and use of evidence-based practice among Canadian doctors of chiropractic: a national survey. J Can Chiropr Assoc. 2015;59:332-48.

32. Schneider MJ, Evans R, Haas M, Leach M, Hawk C, Long C, et al. US chiropractors' attitudes, skills and use of evidence-based practice: a cross-sectional national survey. Chiropr Man Therap. 2015;23:16.

33. Leach MJ, Gillham D. Are complementary medicine practitioners implementing evidence based practice? Complement Ther Med. 2011; 19:128-36.

34. Snow JE, Leach MJ, Clare BA. Attitudes, skill and use of evidence-based practice among US Western herbal medicine providers: a national survey. J Complement Integr Med. 2017;14. 
35. Sullivan M, Leach M, Snow J, Moonaz S. Understanding north American yoga therapists' attitudes, skills and use of evidence-based practice: a crossnational survey. Complement Ther Med. 2017;32:11-8.

36. Leach MJ, Hofmeyer A, Bobridge A. The impact of research education on student nurse attitude, skill and uptake of evidencebased practice: a descriptive longitudinal survey. J Clin Nurs. 2015; 25:194-203

37. Leach MJ, Gillham D. Evaluation of the evidence-based practice attitude and utilization SurvEy for complementary and alternative medicine practitioners. Eval Clin Pract. 2008;14:792-8.

38. Terhorst L, Leach M, Bussières A, Evans R, Schneider MJ. Evaluating the psychometric properties of the evidence-based practice attitude and utilization survey. J Altern Complement Med. 2016;22:328-35.

39. Konstan JA, Rosser BRS, Ross MW, Stanton J, Edwards WM. The story of subject naught: a cautionary but optimistic tale of internet survey research. J ComputMediat Commun. 2005;10:00.

40. Mahmood K. Do people overestimate their information literacy skills? A systematic review of empirical evidence on the dunning-Kruger effect. Commun Inf Lit. 2016;10:198-213.

41. Yahui HC, Swaminathan N. Knowledge, attitudes, and barriers towards evidence-based practice among physiotherapists in Malaysia. Hong Kong Physiother J. 2017;37:10-8.

42. Salbach NM, Jaglal SB, Korner-Bitensky N, Rappolt S, Davis D. Practitioner and organizational barriers to evidence-based practice of physical therapists for people with stroke. Phys Ther. 2007:87:1284-303.

43. Veziari Y, Leach MJ, Kumar S. Barriers to the conduct and application of research in complementary and alternative medicine: a systematic review. BMC Complement Altern Med. 2017:17:166

44. Fell DW, Burnham JF, Dockery JM. Determining where physical therapists get information to support clinical practice decisions. Health Info Libr J. 2013;30:35-48

45. Leach MJ, Tucker B. Current understandings of the research-practice gap from the viewpoint of complementary medicine academics: a mixedmethod investigation. Explore. 2017;13:53-61.

46. Steel A, Sundberg T, Reid R, Ward L, Bishop FL, Leach M, et al. Osteopathic manipulative treatment: a systematic review and critical appraisal of comparative effectiveness and health economics research. Musculoskelet Sci Pract. 2017;27:165-75.

47. Fernández-de-Las-Peñas C, Ortega-Santiago R, Díaz HF, Salom-Moreno $J$, Cleland JA, Pareja JA, et al. Cost-effectiveness evaluation of manual physical therapy versus surgery for carpal tunnel syndrome: evidence from a randomized clinical trial. J Orthop Sports Phys Ther. 2019;49: 55-63.

48. Zhu L, Wei $X$, Wang S. Does cervical spine manipulation reduce pain in people with degenerative cervical radiculopathy? A systematic review of the evidence, and a meta-analysis. Clin Rehabil. 2016;30: $145-55$.

49. Thomson OP, Petty NJ, Moore AP. Clinical reasoning in osteopathy - More than just principles? Int J Osteopathic Med. 2011;14:71-6.

50. Majid S, Foo S, Luyt B, Zhang X, Theng YL, Chang YK, et al. Adopting evidence-based practice in clinical decision making: nurses' perceptions, knowledge, and barriers. J Med Libr Assoc. 2011;99:229-36.

51. Prior P, Wilkinson J, Neville S. Practice nurse use of evidence in clinical practice: a descriptive survey. Nurs Prax N Z. 2010;26:14-25.

52. Ramirez-Velez R, Correa-Bautista JE, Munoz-Rodriguez DI, Ramirez L, Gonzalez-Ruiz K, Dominquez-Sanchez MA, et al. Evidence-based practice: beliefs, attitudes, knowledge, and skills among Colombian physical therapists. Colomb Med. 2015;46:33-40.

53. Jette DU, Bacon K, Batty C, Carlson M, Ferland A, Hemingway RD, et al. Evidence-based practice: beliefs, attitudes, knowledge, and behaviors of physical therapists. Phys Ther. 2003;83:786-805.

54. Hall G. Attitudes of chiropractors to evidence-based practice and how this compares to other healthcare professionals: a qualitative study. Clin Chiropr. 2011;14:106-11.

55. Walker BF, Stomski NJ, Hebert JJ, French SD. A survey of Australian chiropractors' attitudes and beliefs about evidence-based practice and their use of research literature and clinical practice guidelines. Chiropr Man Therap. 2013;21:44.

56. Sadeghi-Bazargani H, Tabrizi JS, Azami-Aghdash S. Barriers to evidencebased medicine: a systematic review. J Eval Clin Pract. 2014;20:793-802.
57. Zwolsman S, Te Pas E, Hooft L, Wieringa-De Waard M, Van Dijk N. Barriers to GPs' use of evidence-based medicine: a systematic review. Br J Gen Pract. 2012;62:e511-21.

58. Leach MJ, Tucker B. Current understandings of the research-practice gap in nursing: a mixed-methods study. Collegian. 2018;25:171-9.

59. Osteopathy Australia. About us. 2018. https://www.osteopathy.org.au/aboutus. Accessed 17 Dec 2018.

\section{Publisher's Note}

Springer Nature remains neutral with regard to jurisdictional claims in published maps and institutional affiliations.
Ready to submit your research? Choose BMC and benefit from:

- fast, convenient online submission

- thorough peer review by experienced researchers in your field

- rapid publication on acceptance

- support for research data, including large and complex data types

- gold Open Access which fosters wider collaboration and increased citations

- maximum visibility for your research: over $100 \mathrm{M}$ website views per year

At BMC, research is always in progress.

Learn more biomedcentral.com/submissions 